\title{
ANALISIS FUNGSI BORDA UNTUK MENGETAHUI TINGKAT PENGETAHUAN TERHADAP KURIKULUM ABAD 21
}

\author{
Elva Susanti ${ }^{1 *}$, Anggia Arista ${ }^{2}$ \\ 1,2Prodi Teknik Industri, Fakultas Teknik dan Komputer, Universitas Putera Batam, \\ Jl. Letjen R. Soeprapto, Batam, Kepulauan Riau, Indonesia 29432. \\ *e-mail: elvasusanti89@gmail.com
}

\begin{abstract}
This study aims to determine the extent of teacher knowledge about the 21st century curriculum by using the BORDA function. There are four skills and abilities namely communication, collaboration, critical and creative. The sample used was junior high and vocational school teachers in Batam. The results of his research communication skills have a greater percentage than other skills, namely for junior high school teacher communication knowledge by $43 \%$ and vocational school by $34 \%$. Whereas in the SWOT analysis skills and communication skills are the strengths that both have a higher value than other indicators, both junior high and vocational high schools.
\end{abstract}

Keywords: Communication, Collaboration, Critical and Creative.

\section{Pendahuluan}

Kurikulum merupakan pedoman dalam proses pembelajaran yang bertujuan untuk meningkatkan pendidikan yang ada. Kementrian pendidikan dan kebudayaan telah memberikan sosialisai pengembangan dari kurikum 2013 yaitu kurikulum abad 21. Nampaknya saat ini sebagian besar sekolah belum siap melakukan peubahan kurikum dan masih menggunakan kurikulum yang lama terkendala dengan proses yang panjang, kurikulum berubah secara otomatis bahan ajar, silabus, Rencana pelaksanaan pembelajaran tentunya harus dirubah sesuai dengan kurikum yang berlaku. Melihat kondisi guru saat ini memiliki beban kerja yang tinggi dengan mengajar minimal 24 sks, belum lagi beban melakukan penelitian tindakan kelas, pembinaan peserta didik, dan kegiatan pendidikan lainnya.

Sebagai seorang pendidik, guru harus memiliki keterampilan dan kecakapan yang baik, mengadakan pembaharuan dan inovasi-inovasi baru dalam proses pembelajaran demi meningkatkan hasil belajar peserta didik. Dalam UU No.14 Tahun 2005 pasal 1, Guru merupakan pendidik yang professional yang tugasnya mendidik peserta didik, mengajar peserta didik, membimbing mereka, mengarahkan, melatih, menilai hasil belajar dan mengevaluasi setiap proses belajar mengajar dan itupun berlaku pada setiap jenjang pendidikan, baik pada pendidikan anak usia dini, pendidikan dasar maupun pendidikan menengah dengan cara menumbuhkan kondisi lingkungan belajar mengajar yang menarik, mampu mengajar, mendidik maupun membimbing siswa (peserta didik) menuju kedewasaan dan kemandirian. (Anugraheni, 2017). Pendidikan yang mendidik tersebut haruslah memiliki strategi pembelajaran dengan cara mengidentifikasi perubahan maupun tingkah laku yang dimiliki peserta didik, mengajar berdasarkan tuntutan perkembangan zaman 
dengan menggunakan metode pembelajaran yang efektif dan efisien berdasarkan norma yang berlaku. Semua itu tidak akan terwujud jika pengetahuan guru kurang baik, terutama pengetahuan terhadap kurikulum yang ada.

Melihat kondisi demikian, penulis ingin mengetahui seberapa besar tingkat pengetahuan guru tentang kurikulum abad 21dan menganalisa kekuatan, kelemahan, peluang dan ancaman yang dimiliki seorang guru dengan menggunakan analisa swot.

\section{Landasan Teori \\ 2.1. Pengertian Pengetahuan}

Pengetahuan adalah merupakan suatu khasanah yang memiliki kekayaan mental secara langsung maupun secara tidak langsung yang memberikan nilai lebih dan turut memperkaya kehidupan kita. Setiap pengetahuan, pastilah memiliki suatu ciri-ciri yang spesifik mengenai apa (ontologi), bagaimana (epistologi) dan untuk apa (aksiologi). Pengetahuan yang dimiliki seseorang, akan mempengaruhi prilakunya, semakin baik pengetahuan seseorang maka prilakunya pun semakin baik (Rajaratenam, 2014).

\subsubsection{Kurikulum Abad 21}

National Education Association mengidentifikasi suatu keterampilan abad ke-21 sebagai keterampilan 4C. yaitu kemampuan berpikir kritis, kreativitas, komunikasi, dan kolaborasi. Keterampilan berpikir kritis merupakan keterampilan dalam melakukan berbagai analisisa, melakukan suatu penilaian, mengeevaluasi, rekonstruksi, dan selanjutnya melakukan pengambilan keputusan berdasarkan tindakan yang logis (King, et al., 2010). Selanjutnya keterampilan kreativitas adalah suatu teknik menghasilkan ide-ide baru, mengelaborasi, menganalisa dan mengevaluasi ide-ide sendiri menghasilkan keorijinalitas suatu inovasi (Redhana, 2019). Kemampuan komunikasi adalah suatu kemampuan yang dapat mengartikulasikan pikiran dan ide-ide secara efektif, mampu mendengarkan dan menuangkan ide kepada diri sendiri maupun orang lain secara nyata. Sedangkan Kolaborasi merupakan kemampuan bekerja sama, saling bersinergi dengan berbagai pihak dan bertanggung jawab dengan diri sendiri, masyarakat maupun lingkungan (Sugiyarti, 2018).

\subsection{Fungsi Borda}

Metode Borda merupakan metode yang ditemukan oleh Jean-Charles de Borda pada abad ke 18. Metode Borda ini bertujuan untuk penentuan dalam penetapan pengambilan keputusan yang berperingkat, dengan melakukan perengkingan terhadap elemen-elemen tertentu atau kandidat yang disusun berdasarkan pilihan pada masing-masing pembuat keputusan. (Zarghami, 2011). Metode borda dapat digunakan untuk mengakomodasi hasil dalam memberikan keputusan. Perhitungan pada fungsi borda ini, menggunakan bobot pada setiap posisi rangking yang dihasilkan oleh masing-masing pembuat keputusan. Alternatif pilihan dengan posisi peringkat atas diberi nilai lebih tinggi dengan kandidat pada posisi peringkat berikutnya dalam suatu perbandingan berpasangan (Apriliani, 2015). Fungsi Borda merupakan pembuat keputusan pemenang dengan pemilihan dengan poin tertentu untuk masing-masing kandidat. Pemilihan dan perhitungan (voting and counting) dilakukan dengan cara memberikan sejumlah point kepada masing-masing calon, dengan kata lain dimana $\mathrm{n}$ kandidat akan menerima $\mathrm{n}$ point untuk pilihan pertama, $n-1$ untuk pilihan kedua, n2 pada pemilihan pilihan $3, \mathrm{n}-4$ untuk pilihan 5 sebanyak $\mathrm{n} !$.

\subsection{Analisa SWOT}

Analisis SWOT merupakan suatu upaya untuk mengenali kekuatan, kelemahan, peluang, dan ancaman dalam suatu kasus. Fungsi dari analisis SWOT adalah untuk menganalisa mengenai kekuatan,kelemahan serta keunggulan kompetitif yang dimiliki oleh perusahaan/organisasi dengan melakukan analisa terhadap kondisi internal, serta analisa mengenai peluang dan ancaman yang dihadapi dan dilakukan melalui analisa terhadap kondisi 
eksternal. Informasi eksternal mengeni peluang dan ancaman dapat diperoleh dari banyak sumber (Asiah, 2017).

\subsubsection{Model Analisis Swot}

1. Strategi SO (Strength-Opportunities) Merupakan suatu strategi yang dibuat berdasarkan jalan pemikiran dengan memanfaatkan seluruh kekuatan untuk merebut dan memanfaatkan peluang yang sebesar-besarnya.

2. Strategi ST (Strenghts-Threats) merupakan strategi dalam menggunakan suatu kekuatan yang dimiliki yang bertujuan untuk mengatasi suatu ancaman.

3. Strategi WO (WeknessesOpportunities). Strategi ini merupakan suatu strategi yang diterapkan berdasarkan pemanfaatan peluang yang ada dengan cara meminimalkan kelemahan yang ada.

4. Strategi WT (Weknesses- Threats) Strategi ini berdasarkan pada kegiatan yang bersifat bertahan dan berusaha meminimalkan kelemahan yang ada serta menghindari ancaman. (Asiah, 2017).

\section{Metodologi Penelitian}

Jenis penelitian ini adalah pendekatakan kuantitatif dan kualitatif mengenai fenomena, persepsi maupun tindakan subjek penelitian. Instrumen penelitian yaitu berupa quisioner maupun wawancara kepada guru-guru dikota Batam yaitu guru SMPN.20, SMP Muhammadyah 1 dan SMK Muhammadyah 1 kota Batam sebagai sampel penelitian ini. Sumber data yang digunakan adalah data primer. Populasi dalam penelitian ini adalah seluruh guru yang ada dikota Batam dengan teknik pengambilan sampel berdasarkan convinence saat pemilihan sekolah dan berdasarkan total sampling saat memilih responden yaitu semua guru SMP n.20, SMP Muhammadyah 1, dan semua guru SMK muhammadyah 1 kota Batam. Sebelum melakukan analisa data, dilakukan uji validitas dan reabilitas data dengan skala likert rumus cronbach's alpha dengan menggunakan SPSS 16. Untuk tingkat pengetahuan dengan menggunakan fungsi borda, quisionernya menggunakan skala nominal 0 dan 1 sedangkan untuk analisa swot digunakan skala likert.

\section{Hasil dan Pembahasan \\ 4.1. Pengujian Instrumen}

Penelitian ini dilakukan dengan penyebaran kuesioner tentang kemampuan keterampilan dan kecakapan abad 21, quisioner keterampilan dengan menggunakan skala nominal digunakan untuk mengetahui tingkat pengetahuan dengan fungsi borda sedangkan sedangkan quisioner kecakapan dengan menggunakan skala likert untuk analisis swot.

\subsubsection{Uji Validitas}

Berikut adalah hasil uji validitas pada quisioner keterampilan abad 21 untuk data SMP dengan total 66 responden, diperoleh $\mathrm{r}$ tabel $\mathrm{df}=$ 66-2 =64 satu arah yaitu 0.2042 dan untuk data SMK total 10 responden $\mathrm{df}=10-2=8$ satu arah diperoleh $r$ tabel yaitu 0.549 .

Untuk melakukan uji validitas, kita harus memperhatikan nilai pada $r$ tabel, dengan melihat selisih antara nilai $r$ hitung dengan $r$ tabel. Apabila $r$ hitung $>r$ tabel maka item pada instrumentpada masing-masing butir soal dikatakan valid.

Tabel 1 dan 2 memiliki nilai $r$ hitung hasil output SPSS lebih besar dari $r$ tabel, misalnya pada butir soal kecakapan untuk dimensi kreatif, butir soal no. 20 nilai $r$ hitung 0.724 dan $r$ tabel 0.2042 pada guru SMP maka dapat dikatakan nilai $\mathrm{r}$ hitung > r tabel maka butir soal nomor 20 dikatakan valid. 
Tabel 1. Tabel Validitas butir soal keterampilan

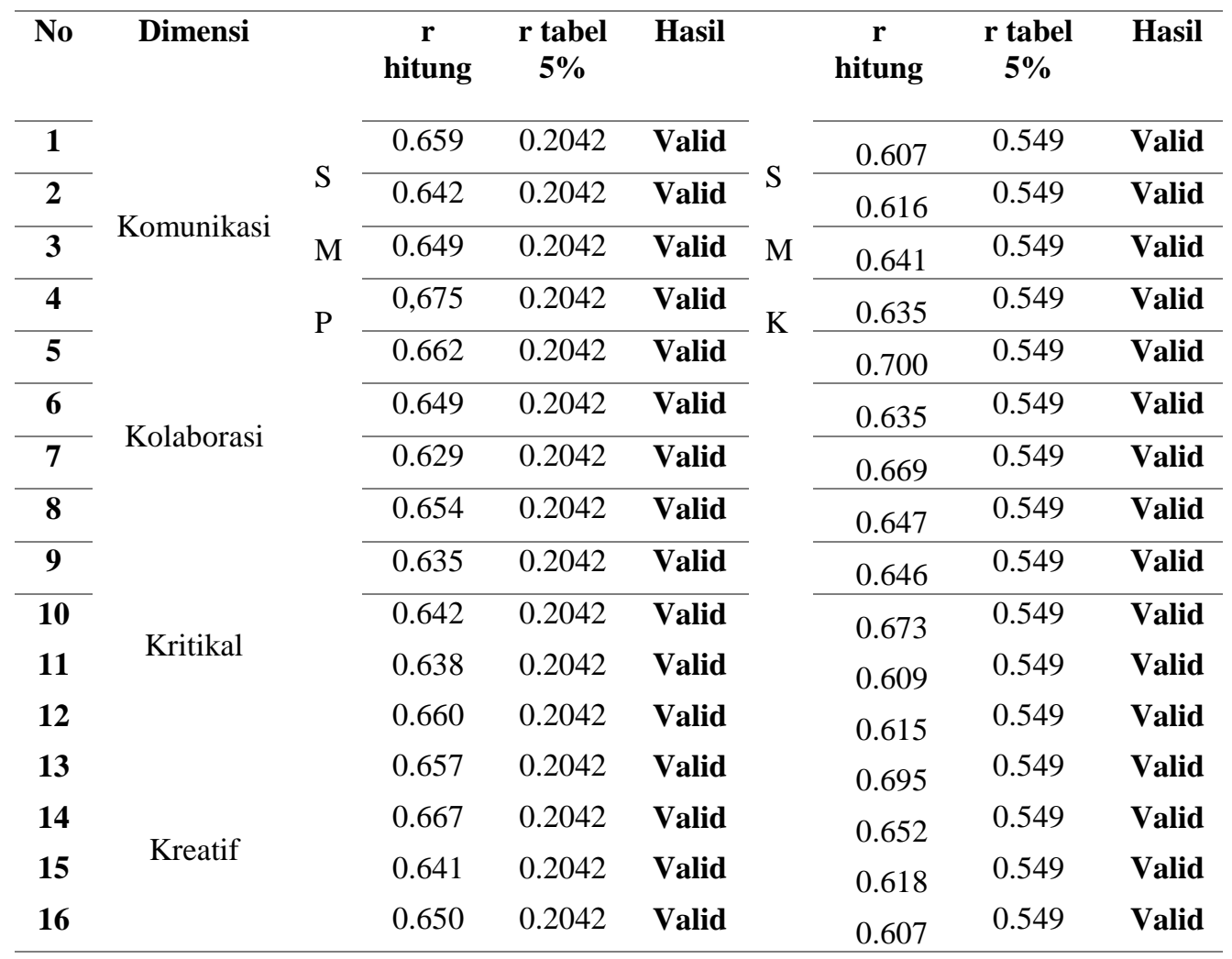

Tabel 2. Tabel Validitas butir soal kecakapan

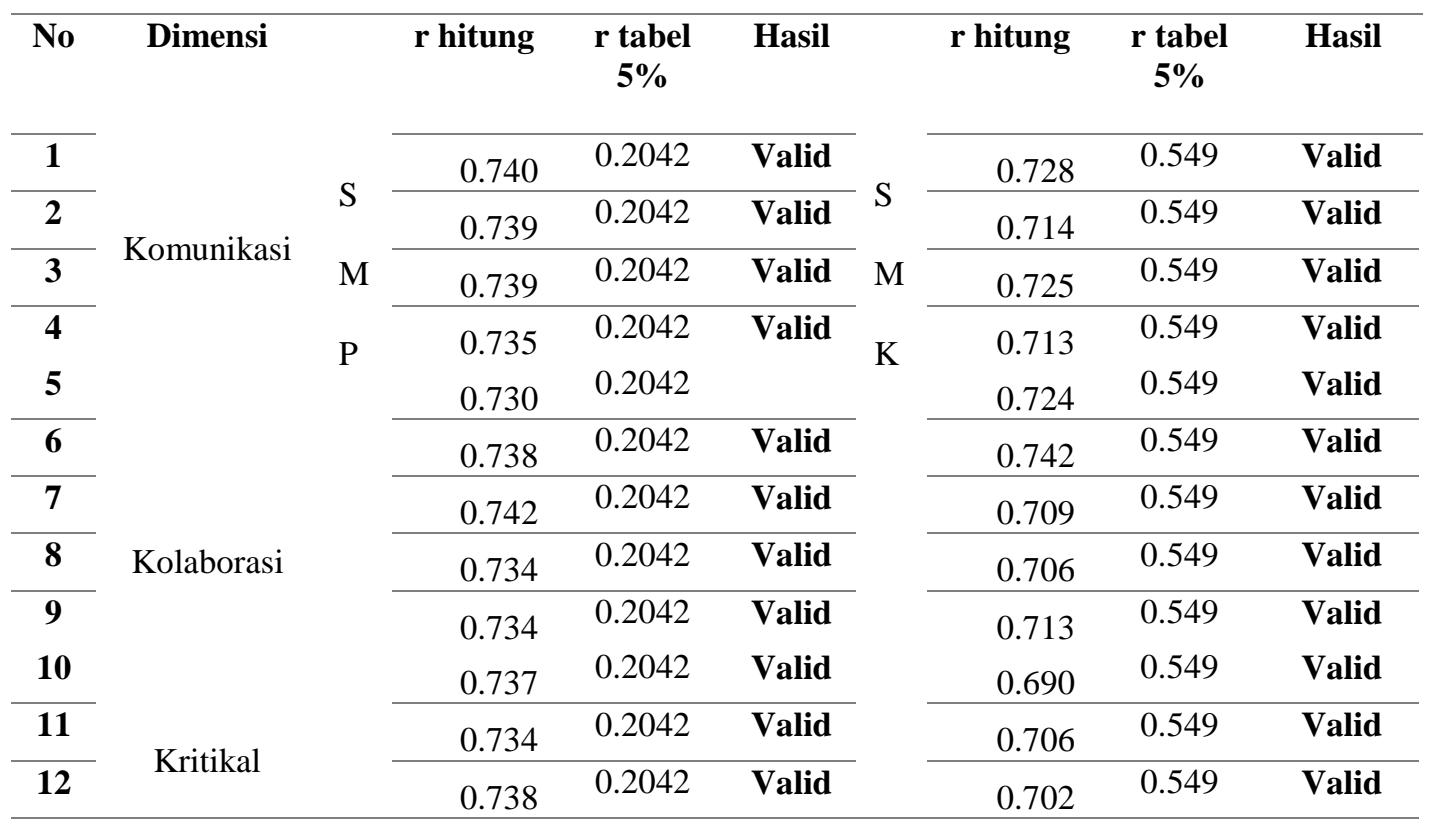




\begin{tabular}{|c|c|c|c|c|c|c|c|}
\hline 13 & & 0.725 & 0.2042 & Valid & 0.716 & 0.549 & Valid \\
\hline 14 & & 0.729 & 0.2042 & Valid & 0.718 & 0.549 & Valid \\
\hline 15 & & 0.729 & 0.2042 & Valid & 0.695 & 0.549 & Valid \\
\hline 16 & & 0.729 & 0.2042 & Valid & 0.718 & 0.549 & Valid \\
\hline 17 & & 0.728 & 0.2042 & Valid & 0.731 & 0.549 & Valid \\
\hline 18 & Kreatif & 0.729 & 0.2042 & Valid & 0.719 & 0.549 & Valid \\
\hline 19 & & 0.725 & 0.2042 & Valid & 0.716 & 0.549 & Valid \\
\hline 20 & & 0.724 & 0.2042 & Valid & 0.719 & 0.549 & Valid \\
\hline
\end{tabular}

\subsubsection{Uji Reabilitas}

Tabel 3. Hasil Uji Reliabilitas SMP dan SMK

\begin{tabular}{|c|c|c|c|}
\hline Dimensi & $\begin{array}{c}\text { Alpha } \\
\text { Cronbach } \\
\text { (ekspektas } \\
\text { i) }\end{array}$ & $\begin{array}{c}\text { Hasi } \\
1\end{array}$ & $\begin{array}{c}\text { Reliabilit } \\
\text { as }\end{array}$ \\
\hline SMP & & $>$ & \\
\hline $\begin{array}{c}\text { Keterampil } \\
\text { an }\end{array}$ & 0,663 & 0,6 & Reliable \\
\hline $\begin{array}{c}\text { SMP } \\
\text { Kecakapan }\end{array}$ & 0,744 & $\begin{array}{l}> \\
0,6\end{array}$ & Reliable \\
\hline $\begin{array}{c}\text { SMK } \\
\text { Keterampil } \\
\text { an }\end{array}$ & 0.658 & $\begin{array}{l}> \\
0,6\end{array}$ & Reliable \\
\hline $\begin{array}{c}\text { SMK } \\
\text { Kecakapan }\end{array}$ & 0.727 & $\begin{array}{l}> \\
0,6\end{array}$ & Reliable \\
\hline
\end{tabular}

Dari output, diketahui nilai alpha Cronbach pada masing-masing dimensi $0.662>$ $0.6,0.744>0.6,0.658>0.6,0.727>0.6$ maka dapat dikatakan bahwa partisipasi guru dalam menjawab kuesioner adalah realible, yang artinya jawabannya konsisten.

Dari tabel 1,2, dan 3menyatakan bahwa data penelian valid dan reliable.

\subsection{Pengolahan data}

\subsubsection{Kompetensi keterampilan abad 21}

Berikut adalah hasil dari pengolahan data fungsi borda dengan menggunakan data untuk SMP dan SMK. Adapun keterampilan 4C terdiri dari Communication,Collaboration, Critical Thinking and problem solving, dan Creative and Innovative atau jika diterjemahkan ke dalam bahasa Indonesianya yaitu keterampilan 4C. yaitu kemampuan berpikir kritis, kreativitas, komunikasi, dan kolaborasi.

$$
\text { Keterangan : }
$$

$\mathrm{KM}=$ kemampuan komunikasi

$\mathrm{KL}=$ kemampuan kolaborasi

$\mathrm{KK}=$ kemampuan berpikir kritis

$\mathrm{KR}=$ kemampuan kreativitas

Tabel 4. Pengolahan fungsi borda pada keterampilan $4 \mathrm{C}$

\begin{tabular}{|c|c|c|c|c|c|c|c|c|c|}
\hline No & & & & npe & tensi & & & SMP & SMK \\
\hline 1 & $\mathrm{KM}$ & $\geq$ & KL & $\geq$ & KK & $\geq$ & KR & 23 & 1 \\
\hline 2 & $\mathrm{KM}$ & $\geq$ & KL & $\geq$ & KR & $\geq$ & KK & 22 & 4 \\
\hline 3 & $\mathrm{KM}$ & $\geq$ & KK & $\geq$ & KL & $\geq$ & KR & 10 & 1 \\
\hline 4 & $\mathrm{KM}$ & $\geq$ & KK & $\geq$ & KR & $\geq$ & KL & 8 & 1 \\
\hline 5 & $\mathrm{KM}$ & $\geq$ & $\mathrm{KR}$ & $\geq$ & KK & $\geq$ & $\mathrm{KL}$ & 7 & 3 \\
\hline 6 & $\mathrm{KM}$ & $\geq$ & $\mathrm{KR}$ & $\geq$ & $\mathrm{KL}$ & $\geq$ & KK & 6 & 3 \\
\hline 7 & $\mathrm{KL}$ & $\geq$ & $\mathrm{KM}$ & $\geq$ & KK & $\geq$ & KR & 14 & 2 \\
\hline 8 & $\mathrm{KL}$ & $\geq$ & $\mathrm{KM}$ & $\geq$ & $\mathrm{KR}$ & $\geq$ & KK & 12 & 4 \\
\hline
\end{tabular}




\begin{tabular}{|c|c|c|c|c|c|c|c|c|c|}
\hline 9 & KL & $\geq$ & KK & $\geq$ & $\mathrm{KM}$ & $\geq$ & $\mathrm{KR}$ & 10 & 2 \\
\hline 10 & $\mathrm{KL}$ & $\geq$ & KK & $\geq$ & $\mathrm{KR}$ & $\geq$ & $\mathrm{KM}$ & 6 & 2 \\
\hline 11 & KL & $\geq$ & $\mathrm{KR}$ & $\geq$ & KK & $\geq$ & $\mathrm{KM}$ & 3 & 1 \\
\hline 12 & $\mathrm{KL}$ & $\geq$ & $\mathrm{KR}$ & $\geq$ & $\mathrm{KM}$ & $\geq$ & $\mathrm{KK}$ & 2 & 3 \\
\hline 13 & KK & $\geq$ & $\mathrm{KL}$ & $\geq$ & $\mathrm{KM}$ & $\geq$ & $\mathrm{KR}$ & 6 & 1 \\
\hline 14 & KK & $\geq$ & $\mathrm{KL}$ & $\geq$ & $\mathrm{KR}$ & $\geq$ & $\mathrm{KM}$ & 3 & 1 \\
\hline 15 & KK & $\geq$ & $\mathrm{KM}$ & $\geq$ & $\mathrm{KL}$ & $\geq$ & $\mathrm{KR}$ & 10 & 1 \\
\hline 16 & KK & $\geq$ & $\mathrm{KM}$ & $\geq$ & $\mathrm{KR}$ & $\geq$ & $\mathrm{KL}$ & 9 & 1 \\
\hline 17 & KK & $\geq$ & $\mathrm{KR}$ & $\geq$ & $\mathrm{KM}$ & $\geq$ & $\mathrm{KL}$ & 6 & 0 \\
\hline 18 & KK & $\geq$ & $\mathrm{KR}$ & $\geq$ & $\mathrm{KL}$ & $\geq$ & $\mathrm{KM}$ & 3 & 0 \\
\hline 19 & $\mathrm{KR}$ & $\geq$ & $\mathrm{KL}$ & $\geq$ & KK & $\geq$ & $\mathrm{KM}$ & 0 & 2 \\
\hline 20 & $\mathrm{KR}$ & $\geq$ & $\mathrm{KL}$ & $\geq$ & $\mathrm{KM}$ & $\geq$ & KK & 3 & 4 \\
\hline 21 & $\mathrm{KR}$ & $\geq$ & KK & $\geq$ & $\mathrm{KL}$ & $\geq$ & $\mathrm{KM}$ & 3 & 0 \\
\hline 22 & $\mathrm{KR}$ & $\geq$ & KK & $\geq$ & $\mathrm{KM}$ & $\geq$ & $\mathrm{KL}$ & 4 & 0 \\
\hline 23 & $\mathrm{KR}$ & $\geq$ & $\mathrm{KM}$ & $\geq$ & KK & $\geq$ & $\mathrm{KL}$ & 2 & 1 \\
\hline 24 & $\mathrm{KR}$ & $\geq$ & $\mathrm{KM}$ & $\geq$ & $\mathrm{KL}$ & $\geq$ & KK & 4 & 3 \\
\hline \multicolumn{8}{|c|}{ TOTAL } & 176 & 41 \\
\hline
\end{tabular}

Dari hasil tabel 4 pada kompetensi keterampilan abad 21 untuk guru SMP, skor paling tinggi yaitu 23 sedangkan SMK yaitu 4, maksudnya dengan total 23 orang yang menjawab bahwa komunikasi lebih paham dibandingkan dengan kolaborasi dibandingkan dengan kritikal dan kreatif untuk guru SMP. Sedangkan pada guru SMK, ada nilai 4 sebanyak 3 buah misalnya pada $\mathrm{KM} \geq \mathrm{KL} \geq \mathrm{KR}$ $\geq \mathrm{KK}$ yang artinya kemampuan komunikasi guru lebih baik dari kemampuan kolaborasi, lebih baik dari kemampuan kreatif dan lebih baik dari kemampuan kritikal sebanyak 4 orang begitupun juga nomor 8 dan 20, misalnya no. $8 \mathrm{KL} \geq \mathrm{KM} \geq$ $\mathrm{KR} \geq \mathrm{KK}$ artinya kemampuan kolaborasi guru lebih baik dari kemampuan kominikasi, lebih baik dari kemampuan kreatif dan lebih baik dari kemampuan kritikal sebanyak 4 orang dan seterusnya.

Persentasi terbesar pada SMP yaitu $43 \%$ dan SMK yaitu 34\%. Pada hasil fungsi borda ini diperoleh dengan cara memililih berapa total nomor 1 sampai 6 dengan kompetensi komunikasi yang lebih baik dari pada kompetensi lainnya nilainya yaitu $23+22+10+8+7+6=76$ sehingga nilai komunikasi dibagi total dan dikalikan dengan 100 maka hasilnya adalah $(76 / 176) * 100 \%=43 \%$, untuk kolaborasi dapat kita lihat nonmor 7 sampai 12 yaitu $14+12+10+6$
$+3+2=47$ sehingga $(47 / 176) * 100 \%=26 \%$ Begitupun untuk guru SMK perhitungannya sama caranya dengan SMP hanya totalnya berbeda.

Tabel 5. Tingkat persentasi hasil fungsi borda pada keterampilan $4 \mathrm{C}$

\begin{tabular}{ccccc}
\hline $\begin{array}{c}\text { KOMPETEN } \\
\text { SI }\end{array}$ & $\begin{array}{c}\text { SM } \\
\text { P }\end{array}$ & \% & SM & K \\
\hline KM & 76 & $43 \%$ & 13 & $32 \%$ \\
KL & 47 & $27 \%$ & 14 & $34 \%$ \\
KK & 37 & $21 \%$ & 4 & $10 \%$ \\
KR & 16 & $9 \%$ & 10 & $24 \%$ \\
\hline TOTAL & $\mathbf{1 7 6}$ & $\mathbf{1 0 0}$ & $\mathbf{4 1}$ & $\mathbf{1 0 0}$ \\
\hline
\end{tabular}

Kemampuan komunikasi pada guru SMP persentasi menjawab benar sebanyak $32 \%$. Kemampuan komunikasi dan kolaborasi pada guru SMK persentase banyak menjawab soal yang benar adalah $28 \%$. 
Tabel 6. Tingkat persentasi tiap-tiap butir soal pada keterampilan 4C

\begin{tabular}{cccccccccc}
\hline & & SMP & & & \multicolumn{3}{c}{ SMK } \\
Soal & KM & KL & KK & KR & Soal & KM & KL & KK & KR \\
\hline 1 & 46 & 43 & 16 & 18 & 1 & 10 & 8 & 6 & 6 \\
2 & 44 & 20 & 26 & 13 & 2 & 8 & 2 & 3 & 7 \\
3 & 18 & 29 & 31 & 20 & 3 & 5 & 8 & 4 & 4 \\
4 & 24 & 21 & 24 & 21 & 4 & 4 & 9 & 4 & 7 \\
\hline Total & $\mathbf{1 3 2}$ & $\mathbf{1 1 3}$ & $\mathbf{9 7}$ & $\mathbf{7 2}$ & Total & $\mathbf{2 7}$ & $\mathbf{2 7}$ & $\mathbf{1 7}$ & $\mathbf{2 4}$ \\
\% & $\mathbf{3 2 \%}$ & $\mathbf{2 7 \%}$ & $\mathbf{2 3 \%}$ & $\mathbf{1 7 \%}$ & $\mathbf{\%}$ & $\mathbf{2 8 \%}$ & $\mathbf{2 8 \%}$ & $\mathbf{1 8 \%}$ & $\mathbf{2 5 \%}$ \\
\hline
\end{tabular}

Tabel 7 Kombinasi strategi matriks SWOT

\begin{tabular}{|c|c|c|}
\hline IFAS & \begin{tabular}{l}
\multicolumn{1}{c}{ STRENGHS (S) } \\
1.Pembelajaran bersifat realistic \\
sehingga siswa mudah memahami \\
2.Mampu berpartisipasi dan \\
berkontribusi \\
3Guru selalu memberikan soal \\
bersifat analisis \\
4.Metode pembelajaran selalu \\
bervariasi
\end{tabular} & \begin{tabular}{ll}
\multicolumn{1}{c|}{ WEAKNESS (W) } \\
1. \\
sembahas kembali materi \\
sebelumnya membuat waktu tic \\
cukup \\
2. Belajar kelompok jarang \\
dilakukan \\
3. Hanya guru yang memahami \\
kedalaman materi. \\
4. Guru hanya menggunakan med \\
yang tersedia disekolah
\end{tabular} \\
\hline $\begin{array}{l}\text { OPPORTUNITIES }(\mathrm{O}) \\
\text { 1.Guru selalu memberikan } \\
\text { penjelasan yang dipahami } \\
\text { peserta didik } \\
\text { 2. Mampu mengembangkan } \\
\text { potensi Masing-masing } \\
\text { 3. Mampu memberikan solusi } \\
\text { 4.Pembelajaran bisa saja } \\
\text { melalui pendekatan IT } \\
\text { mengikuti perkembangan } \\
\text { zaman }\end{array}$ & $\begin{array}{l}\text { STRATEGI SO: } \\
\text { 1.Pelatihan pembuatan media } \\
\text { pembelajaran, r model } \\
\text { pembelajaran, maupun evaluasi } \\
\text { pembelajaran hendaknya } \\
\text { diberikan kepada guru, bukan } \\
\text { hanya wakil kurikulum saja dan } \\
\text { itupun harus sering diberikan }\end{array}$ & $\begin{array}{l}\text { STRATEGI WO: } \\
\text { 1. Media pembelajaran sudah } \\
\text { ada dalam bentuk e modul } \\
\text { seharusnya benar-benar } \\
\text { diterapkan agar siswa mudah } \\
\text { memahami dan tidak } \\
\text { kekurangan waktu. } \\
\text { 2. Aplikasi sigil dan reasily } \\
\text { yang sudah ada, sebaiknya } \\
\text { semua guru } \\
\text { menggunakannya. }\end{array}$ \\
\hline $\begin{array}{l}\text { TREATHS (T) } \\
\text { 1. Pembelajaran hanya } \\
\text { dilakukan sesuai keinginan } \\
\text { siswa } \\
\text { 2. Peserta didik selalu bekerja } \\
\text { sama dalam setiap } \\
\text { kesempatan } \\
\text { 3. Contoh dan bukti selalu } \\
\text { bersumber dari guru } \\
\text { 4. Setiap peserta didik memiliki } \\
\text { kemampuan berbeda } \\
\text { sehingga yang kreatif hanya } \\
\text { yang kemampuan tinggi }\end{array}$ & $\begin{array}{l}\text { STRATEGI ST: } \\
\text { 1. Membiasakan peserta didik } \\
\text { dengan kurikulum yang baru } \\
\text { agar mampu berpikir kritis, } \\
\text { kreatif }\end{array}$ & $\begin{array}{l}\text { STRATEGI WT: } \\
\text { 1. Hendaknya dilakukan } \\
\text { metode pembelajaran } \\
\text { yang bukan hanya } \\
\text { metode ceramah saja } \\
\text { tetapi r model } \\
\text { pembelajaran kooperatif } \\
\text { agar ide diperoleh } \\
\text { bersumber dari siswa } \\
\text { dan dipersentasikan } \\
\text { didepan kelas. }\end{array}$ \\
\hline
\end{tabular}




\subsubsection{Analisis SWOT}

Berikut analisa swot bersifat kualitatif, berdasarkan hasil quisoner dari kecakapan abad 21 berdasarkan masing-masing keempat indikator.

Analisa dapat dilihat dari segi internal maupun eksternal, unsur-unsur yang sering dihadapi eksternal maupun internal yaitu setiap hal pastilah memiliki unsur internal seperti memiliki strengths (kekuatan), weaknesses ( kelemahan ), dan memiliki unsur eksternal yang berhadapan dengan oppotunities (peluang) dan threats (ancaman). EFAS adalah external Factors Analysis Summary yang artinya analisa berdasarkan faktor eksternal yang mempengaruhinya sedangkan IFAS adalah Internal Factors Analysis Summary yang merupakan analisa faktor internal yang mempengaruhinya.

Berikut adalah tabel analisi swot pada analisa IFAS maupun EFAS pada kondisi guru secara umum baik SMP maupun SMK yang diperoleh oleh peneliti.

Berikut adalah gambar hasil dari masing-masing kekuatan,kelemahan, peluang dan ancaman pada setiap sekolah SMP (berwarna biru) dan SMK (berwarna merah) untuk menggambarkan keterampilan dan kecakapan pada masing-masing indikator 4C.

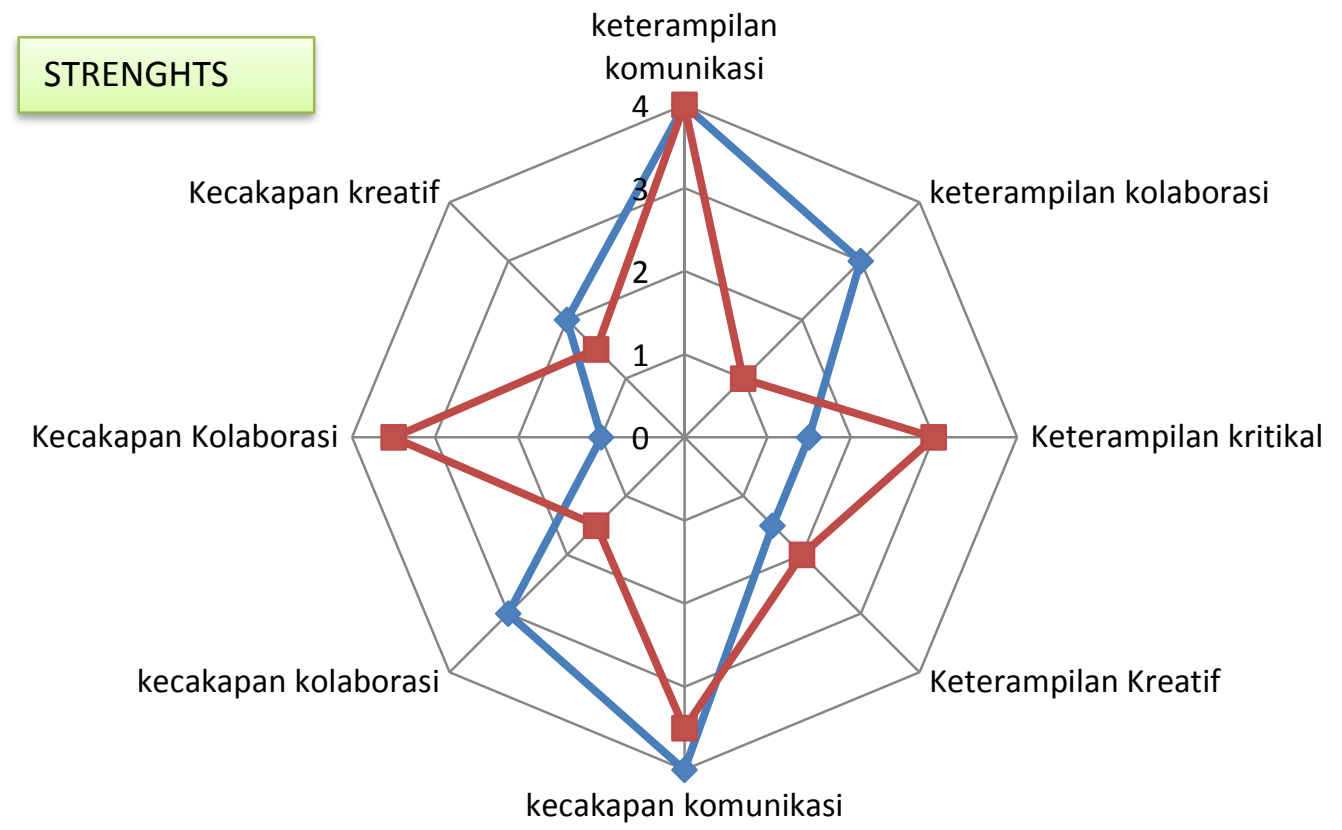

Gambar 1. Kekuatan 


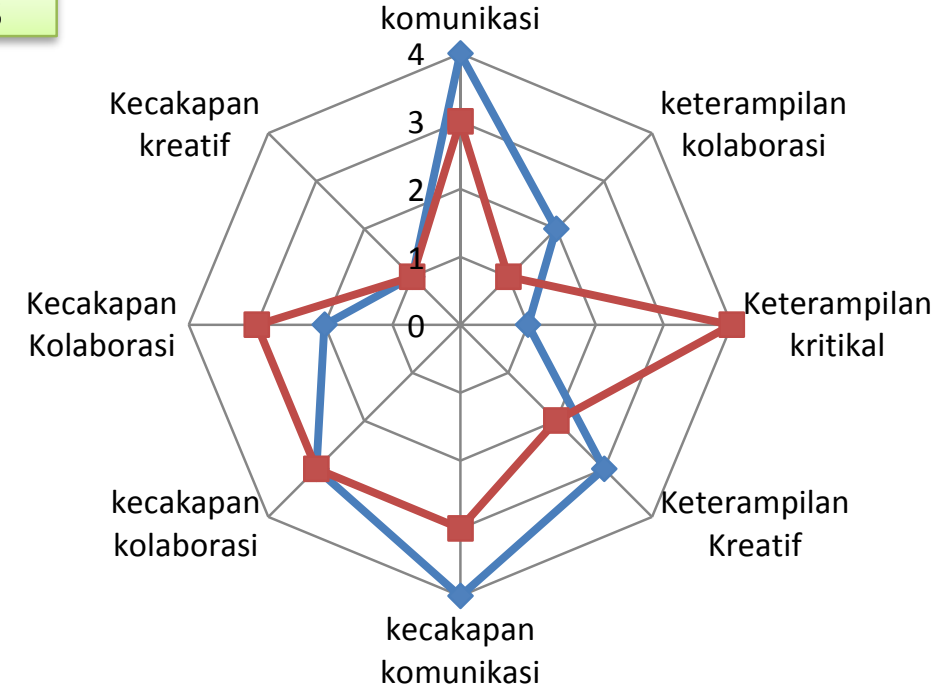

Gambar 2. Kelemahan

Dari gambar terlihat kekuatan keterampilan komunikasi lebih besar dibandingkan indikaor lainnya baik SMP maupun SMK, sedangkan pada kelemahan SMP lemah diketerampilan kritikal, SMK lemah diketerampilan kreatif. Dilihat dari guru SMK yang hanya menerapkan "e-modul" cuma satu orang saja.

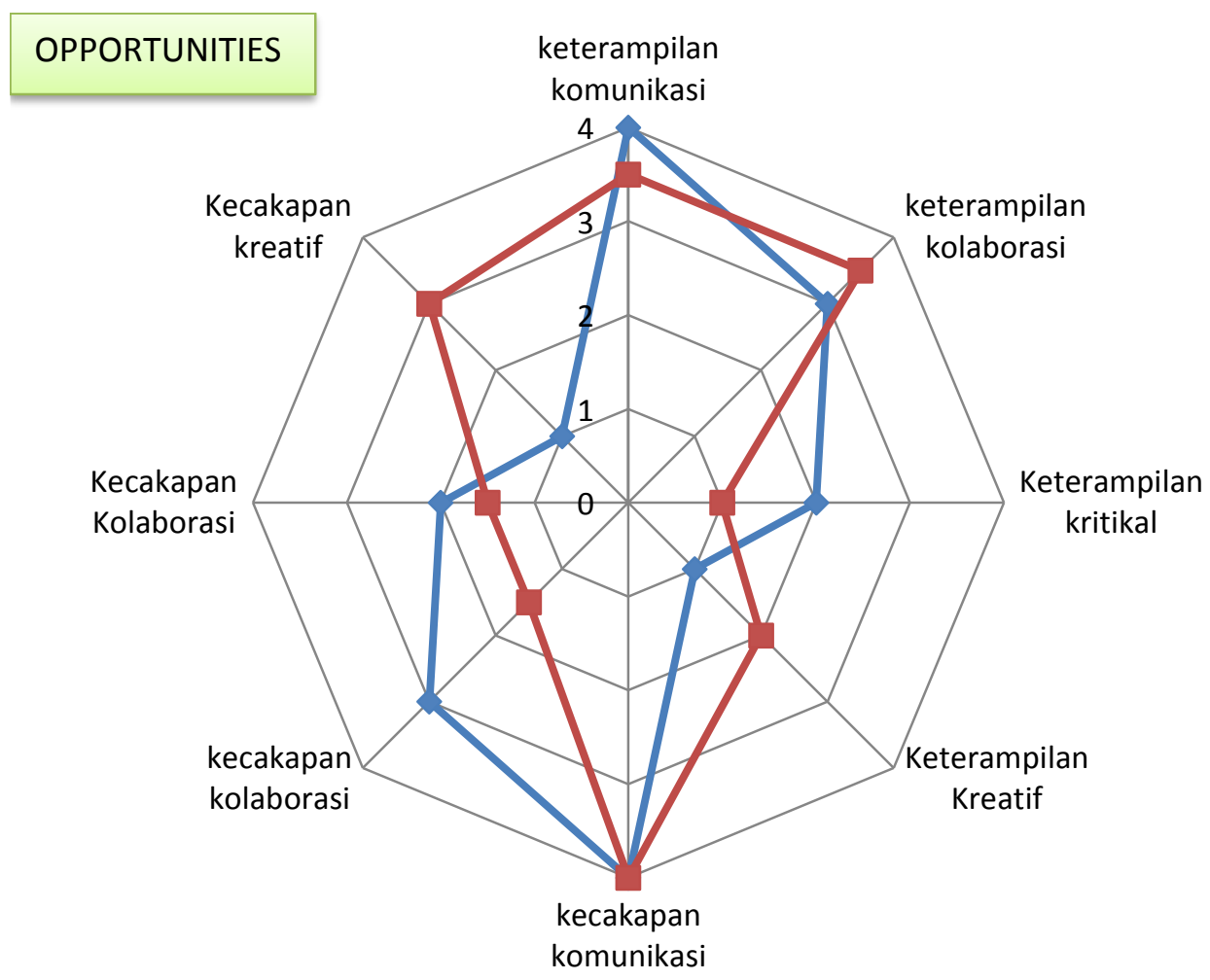

Gambar 3. Peluang 


\section{THREATS}

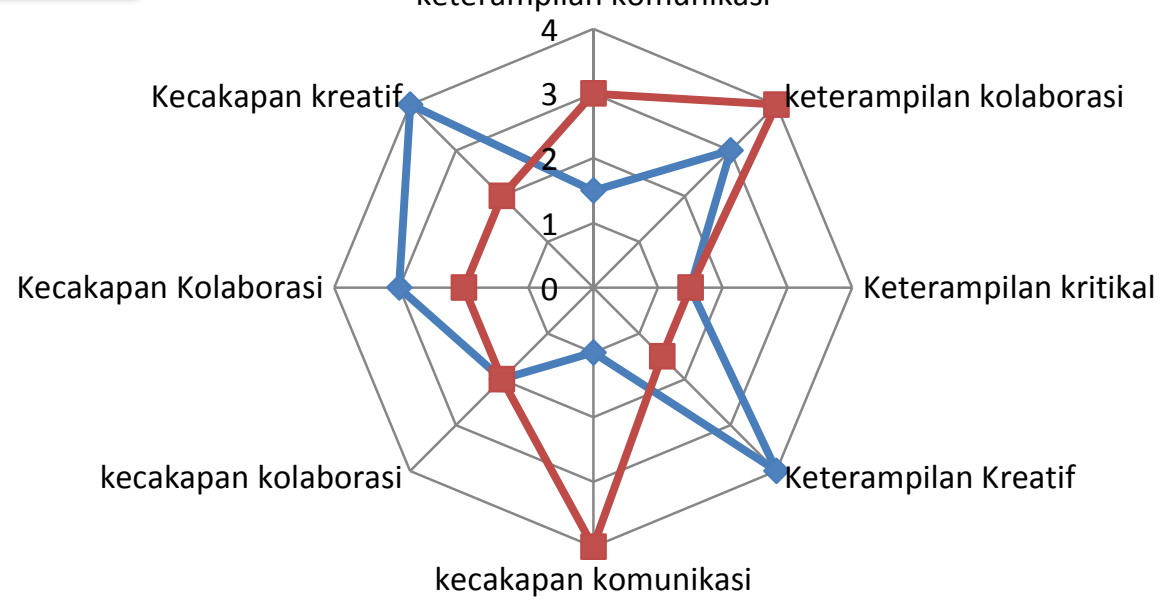

Gambar 2. Ancaman

Peluang Kecakapan komunikasi antara SMP dan SMP adalah nilai yang paling tinggi dibandingkan dengan keterampilan dan kecakapan lainnya. Sedangkan ancaman yang tinggi pada SMP diketerampilan dan kecakapan indikaor kreatif karena rendahnya kreatifitas guru SMP, sedangkan keterampilan kolaborasi dan kecakapan komunikasi ancaman tinggi pada SMK.

\section{Kesimpulan}

Pada hasil fungsi borda, kompetensi keterampilan abad 21 guru SMP menyatakan bahwa kompetensi keterampilan kolaborasi lebih baik daripada kompetensi keterampilan komunikasi lebih baik daripada kompetensi kritikal lebih baik daripada kreatif. Sedangkan pada guru SMK, kompetensi komunikasi lebih baik dari kompetensi kritikal lebih baik dari kompeftensi kreatif dan lebih baik dari kompetensi kolaborasi.

Tingkat persentasi keterampilan kolaborasi pada guru SMP lebih tinggi yaitu sebesar $43 \%$ sedangkan keterampilan kolaborasi pada guru SMK lebih tinggi sebesar 34\%.

Pada analisis swot kekuatan dan peluang memiliki nilai yang sama antara guru SMP dan SMK pada keterampilan dan kecakapan komunikasi.

\section{Ucapan Terima Kasih}

Kami menyampaikan terima kasih kepada beberapa pihak :

1. Simlitabmas Dikti yang memberikan pendanaan penelitian pada penelitian dosen pemula.

2. Universitas Putera Batam yang telah memberikan fasilitas maupun dukungan.

\section{Daftar Referensi}

Anugraheni, Indri. (2017). Analisa Faktor -faktor yang mempengaruhi Proses Belajar GuruGuru Sekolah dasar. Jurnal Manajemen Pendidikan. e-ISSN 2549-9661 Volume: 4, No. 2, J. Magister Manajemen Pendidikan, FKIP Universitas Kristen Satya Wacana.

Apriliani, Dyah. Dkk. (2015). Implementasi Metode Promethee dan Borda Dalam Sistem Pendukung Keputusan Pemilihan Lokasi Pembukaan Cabang Baru Bank. Jurnal Sistem Informasi Bisnis 02(2015). http://ejournal.undip.ac.id/index.php/jsinbi s.

Asiah, Daulika Nur. (2017). Analisis SWOT Tahun 2017 Sebagai Pertimbangan Menetapkan Strategi Tahun 2018-2020 Pada PT. Asfiyak Graha Medika. Simki-Economic Vol. 01 No. 05 Tahun 2017. Universitas Nusantara PGRI Kediri. 
King, F.J., Goodson, L., M.S., dan Rohani, F., 2010, Higher Order Thinking Skills. Assessment dan Evaluation Educational Service Program.

Mahdi. Sistem Pendukung Keputusan Kelompok Pemilihan Dayah Terbaik Menggunakan Metode Promethee Dan Metode Borda. Prosiding. Politeknik Negeri Lhokseumawe.

Rajaratenam, dkk. (2014). Hubungan Tingkat Pengetahuan dan Sikap dengan Tindakan Pencegahan Osteoporosis pada Wanita Usila di Kelurahan Jati. Jurnal Kesehatan Andalas. Fakultas Kedokteran Universitas Andalas Padang.

Redhana, I Wayan. (2019). Mengembangkan Keterampilan Abad Ke-21 Dalam Pembelajaran Kimia. Jurnal Inovasi Pendidikan Kimia, Vol 13, No 1, 2019.

Sugiyarti, Lina.Dkk.(2018). Pembelajaran Abad 21 Di Sd. Prosiding Seminar dan Diskusi Nasional Pendidikan Dasar 2018 ISSN: 2528-5564.

Zarghami, M., (2011). Soft computing of the Borda count by fuzzy linguistic quantifiers. Applied Soft Computing 11, 1067-1073. 